\title{
Toughening of PHBV/PBS and PHB/PBS blends via in situ compatibilization using dicumyl peroxide as a free-radical grafting initiator
}

\section{Citation for published version (APA):}

Ma, P., Hristova - Bogaerds, D. G., Lemstra, P. J., Zhang, Y., \& Wang, S. (2011). Toughening of PHBV/PBS and $\mathrm{PHB} / \mathrm{PB} B \mathrm{~S}$ blends via in situ compatibilization using dicumyl peroxide as a free-radical grafting initiator. Macromolecular Materials and Engineering, 297(5), 402-410. https://doi.org/10.1002/mame.201100224

DOI:

10.1002/mame.201100224

Document status and date:

Published: 01/01/2011

\section{Document Version:}

Accepted manuscript including changes made at the peer-review stage

\section{Please check the document version of this publication:}

- A submitted manuscript is the version of the article upon submission and before peer-review. There can be important differences between the submitted version and the official published version of record. People interested in the research are advised to contact the author for the final version of the publication, or visit the DOI to the publisher's website.

- The final author version and the galley proof are versions of the publication after peer review.

- The final published version features the final layout of the paper including the volume, issue and page numbers.

Link to publication

\footnotetext{
General rights

- You may freely distribute the URL identifying the publication in the public portal. follow below link for the End User Agreement:

www.tue.nl/taverne

\section{Take down policy}

If you believe that this document breaches copyright please contact us at:

openaccess@tue.nl

providing details and we will investigate your claim.
}

Copyright and moral rights for the publications made accessible in the public portal are retained by the authors and/or other copyright owners and it is a condition of accessing publications that users recognise and abide by the legal requirements associated with these rights.

- Users may download and print one copy of any publication from the public portal for the purpose of private study or research.

- You may not further distribute the material or use it for any profit-making activity or commercial gain

If the publication is distributed under the terms of Article $25 \mathrm{fa}$ of the Dutch Copyright Act, indicated by the "Taverne" license above, please 


\title{
Toughening of PHBV/PBS and PHB/PBS Blends via In situ Compatibilization Using Dicumyl Peroxide as a Free-Radical Grafting Initiator
}

\author{
Piming Ma, ${ }^{*}$ Denka G. Hristova-Bogaerds, Pieter Jan Lemstra, Yong Zhang, \\ Shifeng Wang
}

PHB/PBS and PHBV/PBS blends are prepared via in situ compatibilization using DCP as a freeradical grafting initiator. A considerable reduction in PBS particle size and a significant increase in the interfacial adhesion between the $\mathrm{PHB}(\mathrm{V})$ and $\mathrm{PBS}$ phases are observed after the compatibilization. The elongation at break of the PHBV/PBS blends was considerably increased. The local deformation mechanism indicates that matrix yielding together with dilatation, deformation, and fibrillation of the PBS particles are responsible for the improved tensile toughness of the compatibilized PHBV/PBS blends. The tensile strength, impact toughness, and elongation at break of injection-molded PHB(homopolymer)/ PBS blends are also increased after in situ compatibilization.
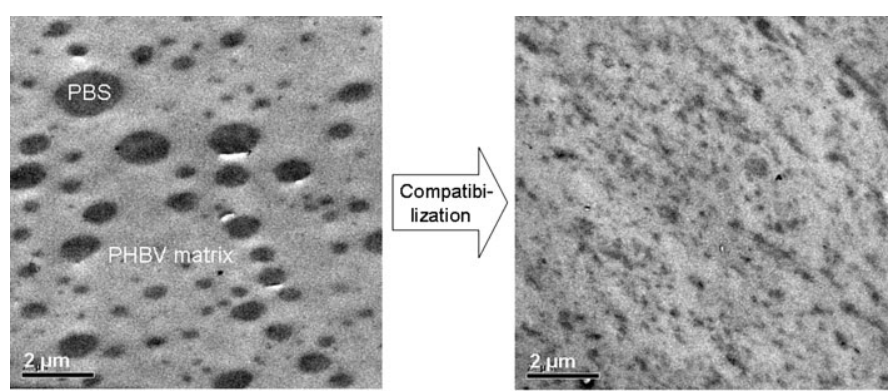

\section{Introduction}

$\operatorname{Poly}(\beta$-hydroxybutyrate) (PHB) and poly[ $(\beta$-hydroxybutyrate)-co-( $\beta$-hydroxyvalerate)] (PHBV), synthesized by bacteria, are semi-crystalline thermoplastics that have attracted considerable attention not only because of their biocompostability and biocompatibility, but also due to their renewable nature. Up to now, the application of PHBbased materials is limited due to their severe brittleness, narrow processing window in view of poor thermal

P. Ma, D. G. Hristova-Bogaerds, P. J. Lemstra

Department of Chemical Engineering and Chemistry, Eindhoven University of Technology, Eindhoven, The Netherlands

E-mail: p.ma@tue.nl

Y. Zhang, S. Wang

School of Chemistry and Chemical Technology, Shanghai Jiao

Tong University, Shanghai, China stability and a low rate of crystallization resulting in aging after molding. ${ }^{[1]}$

The toughness and processability of PHB can be improved by incorporation of the hydroxyvalerate (HV) monomers in the bacterial fermentation process. PHBV with a high HV content has high flexibility, low crystallinity, and low crystallization rate. Increasing HV content compromises the yield strength and Young's modulus of PHB, which can result in rubbery materials, meanwhile, increases the cost of materials. Consequently, it is of interest to find a more useful way to modify the properties of PHB and PHBV with low HV content.

Blending PHB-based materials with other polymers is an effective and economic way to tune their properties. Polymers, such as poly(ethylene oxide), ${ }^{[2,3]}$ poly(vinyl alcohol), ${ }^{[4]}$ poly(lactic acid) (PLA), ${ }^{[5,6]}$ cellulose fiber, ${ }^{[7]}$ poly( $\varepsilon$-caprolactone) (PCL), ${ }^{[8,9]}$ poly(propylene carbonate) (PPC), ${ }^{[10,11]}$ poly(butylene succinate) (PBS), ${ }^{[12,13]}$ poly(ethylene succinate) (PES), ${ }^{[14]}$ and poly[(butylene adipate)-co- 
terephthalate] (PBAT), ${ }^{[15]}$ have been blended with PHB or PHBV to produce even biocompostable materials based on various standards (e.g., EN 13432).

However, the toughness of PHB or PHBV in the above mentioned blends was not significantly improved, probably due to a complete phase separation and a poor interfacial adhesion between PHB (or PHBV) and the other polymers. Moreover, no efficient compatibilizer and compatibilization technique have been reported yet to improve the interfacial adhesion of PHB-based blends. In another study, the ductility of PHBV (HV content = $12 \mathrm{~mol} \%$ ) was considerably enhanced by incorporation of 20 wt\% bisphenol-A (BPA) ascribed to a formation of hydrogen bond network between the two components. ${ }^{[16]}$ The yield strength and elongation at break of the PHBV/BPA $(80: 20)$ blend were reported to be $16 \mathrm{MPa}$ and $370 \%$, respectively.

BPA can improve the tensile toughness of PHBV, but it is not biocompostable and its impact on the environment is not clear yet. Compared with BPA, PBS may be an ideal alternative. PBS is a condensation polymer of succinic acid and 1,4-butanediol, and the two monomers can be derived from renewable resources via fermentation. ${ }^{[17-19]}$ Thus, PHBV/PBS and PHB/PBS blends can retain both compostable and renewable characteristics. PBS is a type of ductile polyester, but is not miscible with PHBV and PHB, except in the solution-casted PHB/PBS (20:80) blend which showed some limited miscibility. ${ }^{[12,13]}$ Compatibilization could be a critical factor in optimizing the mechanical properties of PHBV/PBS and PHB/PBS blends, since the mechanical properties of a multiphase system are usually driven by the ability of the interface to transmit stress from one phase to the other. ${ }^{[20]}$ Compatibilization in polymer blends can be performed by either addition of pre-made copolymers or by an in situ reaction between the polymers during blending. In PLA/PCL ${ }^{[21,22]}$ and PLA/PBS ${ }^{[23]}$ blends, a free radical initiator, i.e., dicumyl peroxide (DCP), was introduced into the melt to induce in situ compatibilization. As a consequence, the particle size of dispersed PCL and PBS reduced significantly accompanied by an increase in interfacial adhesion, resulting in an improved toughness of the PLA/PCL and PLA/PBS blends.

Although considerable work has been devoted to the miscibility and crystallization behavior of PHBV/PBS and $\mathrm{PHB} / \mathrm{PBS}$ blends, rather less attention has been paid to their mechanical properties and interfacial modification (compatibilization). Additionally, most PHB-based blends in previous studies were prepared via a solvent-casting technique, ${ }^{[2-14]}$ which is not very feasible industrially and not environmentally friendly.

The primary objective of this paper is to provide a toughening method for PHB-based materials by reactive compatibilization during melt blending with PBS in the presence of DCP. This method would enable creation of materials with novel performance and could possibly broaden the application range of PHB and PHBV. In the first part of this paper, PHBV (copolymer)/PBS blends with varying amount of DCP were prepared in a Haake mixer to study the toughening effect and mechanisms. In the second part, PHB homopolymer/PBS/DCP blends with varying PBS content were prepared via extrusion to demonstrate that the toughening method is also effective on the PHB homopolymer and to evaluate the feasibility of continuous production.

\section{Experimental Section}

\subsection{Materials}

The PHBV copolymer with an HV content of 12.7 mol\%, measured by means of ${ }^{1} \mathrm{H}$ NMR spectroscopy, was provided by Tianan Biologic Material Co., Ltd., Ningbo, China. Its molar mass was measured based on viscosity in chloroform at $30^{\circ} \mathrm{C}$ and yielded $\bar{M}_{\eta}=250 \mathrm{kDa}$ according to the equation ${ }^{[24]}[\eta]=1.18 \times 10^{-4} \cdot \bar{M}_{\eta}^{0.78}$, where $[\eta]$ is the intrinsic viscosity. PHB (containing $\approx 1 \mathrm{~mol} \% \mathrm{HV}$ ) was provided by the same company with $\bar{M}_{\eta}=200 \mathrm{kDa}$. Due to the very low HV content this sample is considered to be a homopolymer and is referred to as PHB in the text. PBS was supplied by Zhejiang Hangzhou Xinfu Pharmaceutical Co., Ltd. China with a melt-flow index (MFI) of $7.8 \mathrm{~g} \cdot(10 \mathrm{~min})^{-1}\left(150^{\circ} \mathrm{C} / 2.16 \mathrm{~kg}\right)$. DCP (purity $\geq$ 99.5\%) with typical half-life time about $1 \mathrm{~min}$ at $171^{\circ} \mathrm{C}$ was purchased from Sinopharm Chemical Reagent Co., Ltd., China.

\subsection{Blend Preparation}

PHBV and PBS were dried in a vacuum oven at $50{ }^{\circ} \mathrm{C}$ for $12 \mathrm{~h}$ before use. PHBV/PBS blends with ratios of 100:0, 90:10, 80:20, 70:30, and $0: 100 \mathrm{wt} \%$, and PHBV/PBS (80:20 wt\%) blends with DCP contents of $0,0.2,0.5$, and 1.0 wt\% were melt-blended in a mixing chamber of a Rheocord 90 Haake Rheometer (Mess-Technic GmbH, Germany) at $170^{\circ} \mathrm{C}$ and $40 \mathrm{rpm}$ (rotation speed) for $4 \mathrm{~min}$. After preheating, the samples were compression molded at $170{ }^{\circ} \mathrm{C}$ for $3 \mathrm{~min}$ into sheets using a compression-molding machine. The compression-molded samples were used for further testing and characterization.

In order to evaluate the feasibility of continuous production and the effectiveness of the in situ compatibilization in PHB homopolymer/PBS blends, the PHB/PBS blends with and without DCP were prepared using a twin-screw extruder $(L / D=41, D=25 \mathrm{~mm})$ with a water-bath cooling system. The setting temperatures along the extruder (from feeder to die) were 40, 160, 160, 160, 160, 160, 165 , and $160^{\circ} \mathrm{C}$, respectively. The screw rotation speed was fixed at 160 rpm. Before feeding, dried PHB and PBS were pre-mixed with DCP in a high-speed mixer at ambient temperature. The extruded pellets were dried before injection molding. The tensile and Izod impact specimen (ASTM standard) were prepared using an injection-molding machine $(L / D=28, D=25 \mathrm{~mm})$. The barrel temperatures were $160,170,170,170$, and $165^{\circ} \mathrm{C}$, respectively, from hopper to nozzle. The mold temperature was kept at $85^{\circ} \mathrm{C}$ to obtain a fast crystallization rate of PHB during holding and cooling. 
A holding time of $5 \mathrm{~s}$ and a cooling time of $15 \mathrm{~s}$ were used. The injection pressure was controlled approximately at $30 \mathrm{MPa}$.

\subsection{Characterization}

Chloroform was used for the extraction experiment, since chloroform is a good solvent for PHB, PHBV, and PBS but not for the crosslinked network. The amount of gel from the PHB(V)/PBS/DCP blends was obtained by extraction in boiling chloroform for $3 \mathrm{~d}$ using a Soxhlet extractor. The gel fraction was calculated via

$$
\text { gel wt. }-\%=\frac{m_{1}}{m_{0}} \times 100 \%
$$

where $m_{0}$ is the original weight of samples and $m_{1}$ is the weight of dry residues obtained after extraction.

Thermogravimetric analysis (TGA, Perkin-Elmer, Inc., USA) was used to analyze the gel composition of the PHBV/PBS/DCP blends. PHBV, PBS, PHBV/PBS blends and the extracted residues were heated from room temperature to $700^{\circ} \mathrm{C}$ in nitrogen atmosphere $\left(40 \mathrm{~mL} \cdot \mathrm{min}^{-1}\right)$ at a heating rate of $20^{\circ} \mathrm{C} \cdot \mathrm{min}^{-1}$

For the PHBV/PBS system, the tensile properties were measured using an Instron 4465 tester (Instron Co., UK) at a crosshead speed of $10 \mathrm{~mm} \cdot \mathrm{min}^{-1}$. The dimensions of the dumbbell-shaped tensile bar were $75 \mathrm{~mm}$ in length, $0.8 \mathrm{~mm}$ in thickness and $4 \mathrm{~mm}$ in width. Notched Izod impact toughness was tested using an impact analyzer (Ray-Ran Test Equipment Ltd., UK) according to ASTM D256. Flexural properties were measured using the Instron 4465 tester according to ASTM D790. The dimensions of the specimen for impact and flexural testing were $63.5 \times 12.7 \times 3.2 \mathrm{~mm}^{3}$. The testing was done at ambient temperature.

The injection-molded dumbbell-shaped tensile bar was $135 \mathrm{~mm}$ long, $3.2 \mathrm{~mm}$ thick, and $12.7 \mathrm{~mm}$ wide. For injection-molded PHB/ PBS blends, the mechanical properties were measured using the same equipments and under the same testing conditions except that a crosshead (tensile) speed of $50 \mathrm{~mm} \cdot \mathrm{min}^{-1}$ was used.

Scanning electron microscopy (SEM, S-2150 Hitachi Co., Japan) was used to characterize the phase morphology of PHBV/PBS/DCP blends. The samples were first fractured in liquid nitrogen and the cryo-fractured surface was observed after sputter-coating with a thin gold layer.

Transmission electron microscopy (TEM) was used to evaluate the phase morphology of $\mathrm{PHB}(\mathrm{V}) / \mathrm{PBS}$ blends. TEM was performed using a Tecnai 20 microscope, operated at $200 \mathrm{KV}$. Ultrathin sections $(70 \mathrm{~nm})$ were obtained at $-40{ }^{\circ} \mathrm{C}$ using a Leica Ultracut S/ FCS microtome. Considering that the $\mathrm{PHB}(\mathrm{V})$ and $\mathrm{PBS}$ have enough electron density contrast, no extra staining was applied.

\section{Results and Discussion}

\subsection{In situ Compatibilization of the PHBV (Copolymer)/PBS Blends}

\subsubsection{Gel Analysis of the PHBV/PBS Blends}

Both PHB(V) and PBS can form branched and/or crosslinked structures with peroxide as pure materials. ${ }^{[25,26]}$ At the

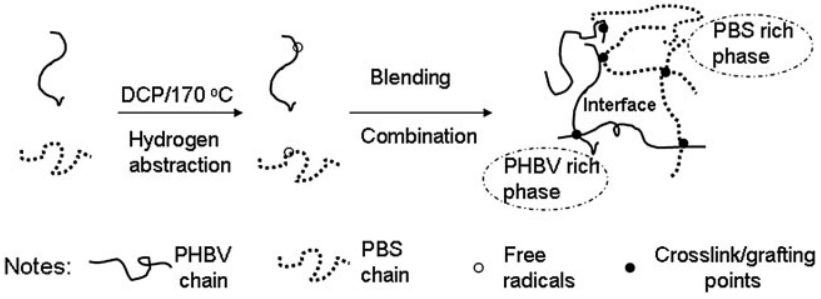

Figure 1. Schematic illustration of the formation of graft copolymers and crosslinked network between the PHBV and PBS components. The possible reactions occurred in the PBS phase or in the PHBV matrix are not present in this scheme.

interface of the PHBV/PBS blends, grafting can occur via a combination of PHBV and PBS free radicals. The formation of PHBV-g-PBS copolymer at the interface is schematically illustrated in Figure 1 . It has to be noted that the combination reaction of free radicals not only occurs at the interface, but can also occur in the PBS domains and in the PHBV matrix. As a consequence, complex reaction products could be obtained, including branched/crosslinked PHBV, branched/crosslinked PBS, PHBV-g-PBS copolymers, and PHBV-crosslink-PBS network. Furthermore, the melt blending was accompanied by chain scissions due to the thermal instability of PHBV and the instability of free radicals, resulting in even more complicated products.

The gel fraction of PHBV/DCP, PBS/DCP, and PHBV/PBS/ DCP blends were calculated based on the extraction experiments. Figure 2 shows the gel fraction of these materials as a function of DCP content. Obviously, the gel fraction of the PHBV/PBS blends steadily increased with the DCP content. This is reasonable since more DCP provides more free radicals. It was also found that the gel fraction of pure PBS was much higher than that of pure PHBV at the same DCP content (0.5 wt\%).

The content of PHBV and PBS in the gel (or blends) can be easily measured via TGA because of the large difference

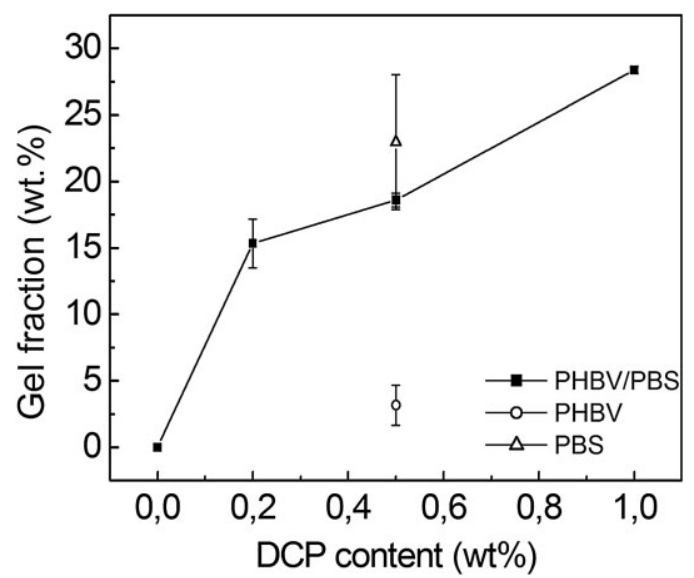

Figure 2. Gel fraction of the PHBV/PBS/DCP (80:20:x), PHBV/DCP and PBS/DCP blends as a function of DCP content.

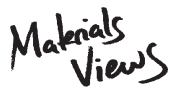

www.MaterialsViews.com
Macromol. Mater. Eng. 2011, 296, 000-000

(c) 2011 WILEY-VCH Verlag GmbH \& Co. KGaA, Weinheim

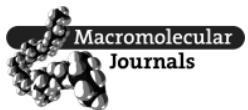




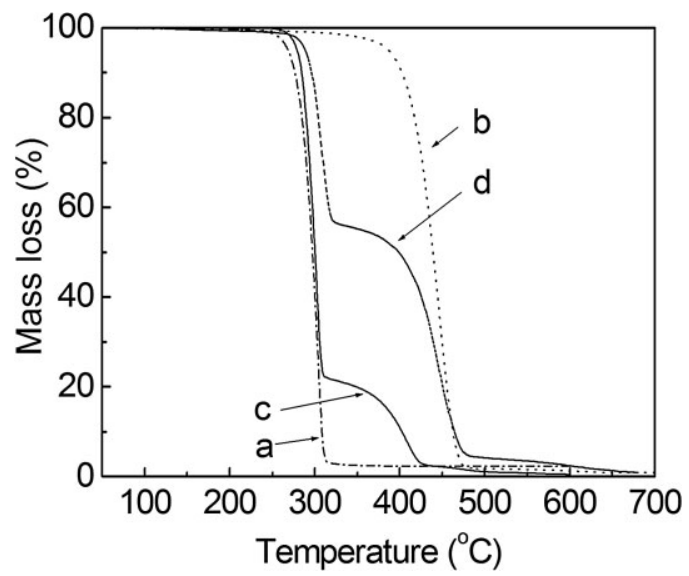

Figure 3. TGA curves of (a) PHBV, (b) PBS, (c) the PHBV/PBS/DCP (80:20:0.5) blend, and (d) gel of the PHBV/PBS/DCP (80:20:0.5) blend.

between the decomposition temperatures of PHBV (ca. $280^{\circ} \mathrm{C}$ ) and PBS (ca. $420^{\circ} \mathrm{C}$ ), and the sharp decomposition temperature sensitivity of the two polymers, as shown in Figure 3. The content of PBS in the initial blends (no DCP) is $20 \mathrm{wt} \%$ (Figure 3c), however, it is much higher (ca. $50 \mathrm{wt} \%$ ) in the gel of PHBV/PBS/DCP blend (Figure 3d). This feature is very important regarding the processability of the compatibilized blends because PBS is the dispersed phase in this study, see below.

\subsubsection{Phase Morphology of the PHBV/PBS Blends}

The morphology of the PHBV/PBS blends was studied by SEM. Figure 4 shows the SEM images of cryo-fractured surface of the physical and compatibilized PHBV/PBS $(80: 20)$ blends. PBS particles and dark holes left by them during fracture were observed on the surface of the physical blend (Figure 4a). The surface of these particles is smooth with clear borders, suggesting a poor compatibility and weak interfacial adhesion between the PHBV and PBS phases. ${ }^{[23]}$ In contrast, no PBS traces were observed on the surface of the compatibilized blend (Figure $4 \mathrm{~b}$ ) probably due
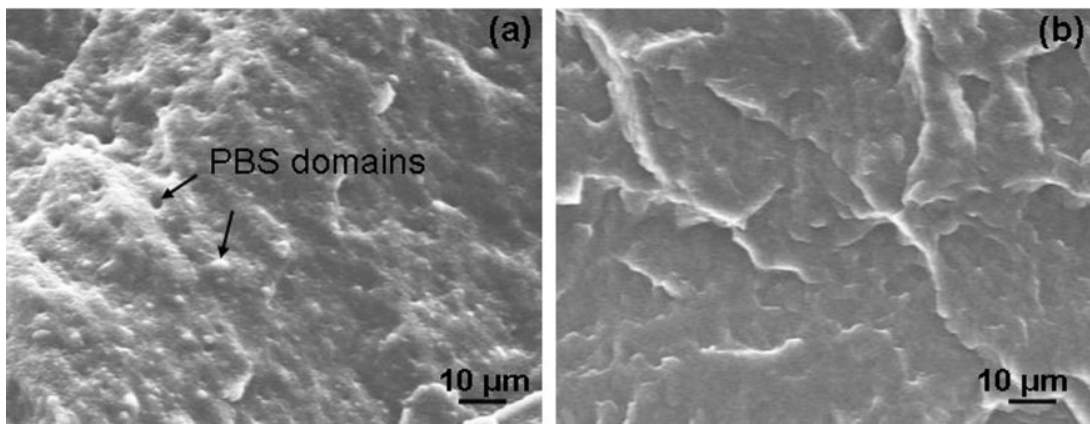

Figure 4. SEM images of the PHBV/PBS (80:20) blends with DCP content: (a) o and (b) 0.5 wt\%. to a considerable decrease in particle size. Hence, little information about the morphology of the PBS in the compatibilized blend can be obtained from SEM.

The morphology of the PHBV/PBS blends with different DCP contents was studied by TEM. The TEM images are shown in Figure 5. Being consistent with the SEM results, the physical PHBV/PBS blend (Figure 5a) shows a typical matrix-droplet morphology with clear domain borders. After addition of DCP to the PHBV/PBS melts, in situ formed PHBV-g-PBS copolymers which acted as compatibilizer between PHBV and PBS, crosslinked PHBV, crosslinked PBS, and a network consisting of both PHBV and PBS were formed. Low concentration of DCP (0.2wt\%) made the dispersion of PBS non-uniform (Figure $5 b$ ), but when the DCP content is $\geq 0.5 \mathrm{wt} \%$, much finer and more uniform dispersion of the PBS was obtained. These results indicate that an emulsifying effect occurred after addition of a sufficient amount of DCP due to the formation of PHBV-gPBS copolymer and PHBV-crosslink-PBS network at the interface of PBS and PHBV phases. Meanwhile, the interface between the PBS domains and the PHBV matrix became less clear after the addition of DCP, which indirectly indicated an improved compatibility between the PHBV and PBS.

\subsubsection{Mechanical Properties of the PHBV/PBS Blends}

The tensile properties of the PHBV/PBS blends (in the absence of DCP) with different weight ratios are shown in Figure 6. The PHBV used in this study is brittle with a low elongation at break (4.5\%), while PBS is ductile with an elongation at break of $260 \%$ and yield strength of $35 \mathrm{MPa}$. The tensile yield strength and the elongation at break of PHBV were only slightly improved by the incorporation of PBS, as shown in Figure 6.

The effect of adding DCP on the mechanical properties of the PHBV/PBS (80:20) blends is shown in Table 1. Compared with other mechanical properties, the elongation at break $\left(\varepsilon_{\mathrm{b}}\right)$ and impact toughness $\left(\sigma_{\mathrm{i}}\right)$ are more sensitive to the compatibilization effect in incompatible binary blends. The physical PHBV/PBS $(80: 20)$ blend in the absence of DCP is brittle with low $\varepsilon_{\mathrm{b}}$ and $\sigma_{\mathrm{i}}$. With $0.2 \mathrm{wt} \% \mathrm{DCP}$, the elongation at break of the blend increased to $200 \%$ indicating a ductile behavior. This could be ascribed to the enhanced interfacial adhesion and the crosslinked network in the blend. With $0.5 \mathrm{wt} \% \mathrm{DCP}$, the $\varepsilon_{\mathrm{b}}$ of the blend was increased by a factor of 50 , thus, the tensile toughness of PHBV/PBS blends was significantly enhanced. However, the notched Izod impact toughness of the PHBV/PBS blends was only slightly improved after applying the compatibilization, i.e., from 2.8 to $5.5 \mathrm{~kJ} \cdot \mathrm{m}^{-2}$. It means the blend after compatibilization is still sensitive to notch, which might 

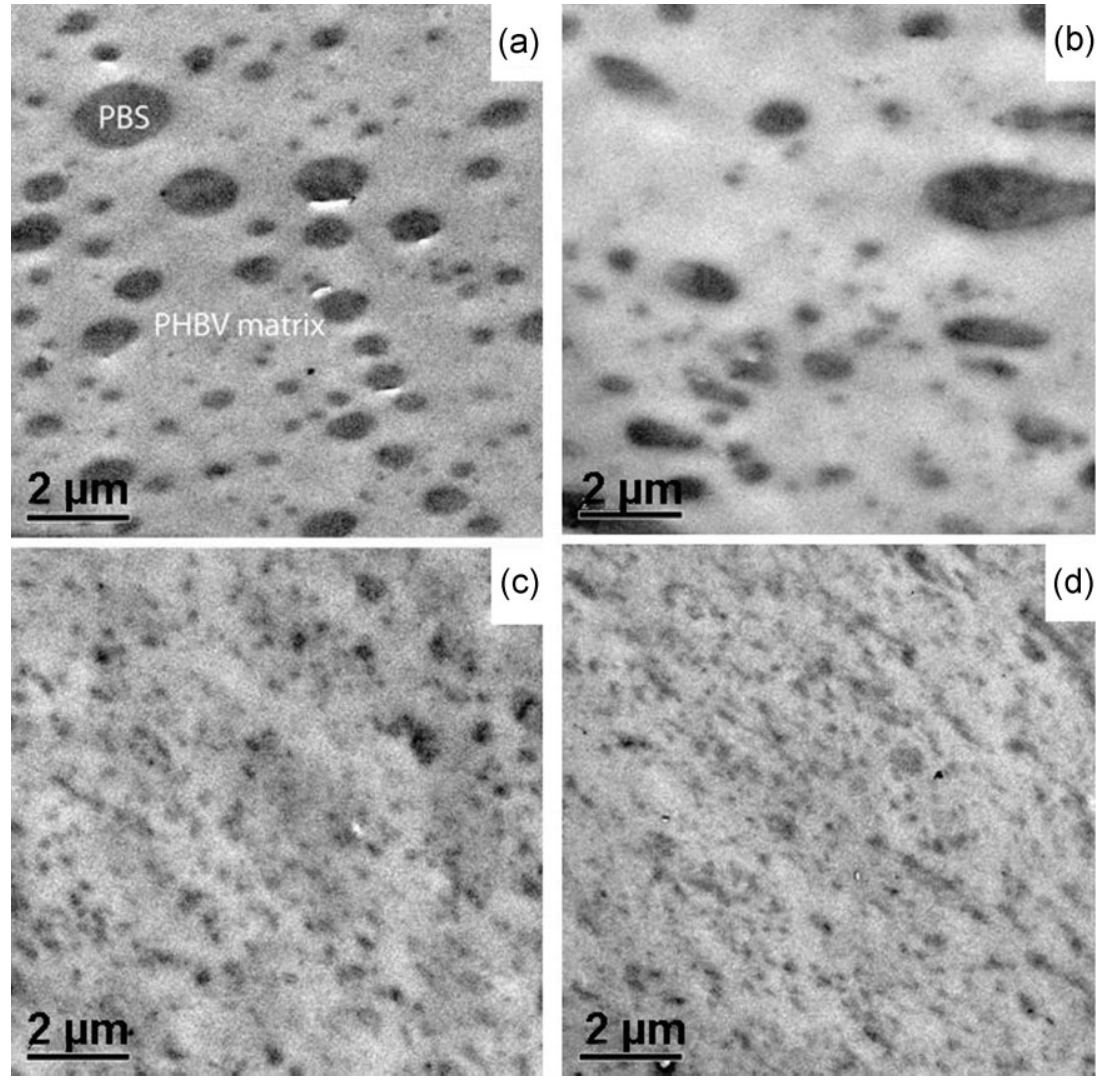

Figure 5. TEM images of the PHBV/PBS (80:20) blends with DCP content of $(a) \circ,(b) 0.2$, (c) 0.5 , and (d) $1.0 \mathrm{wt} \%$.

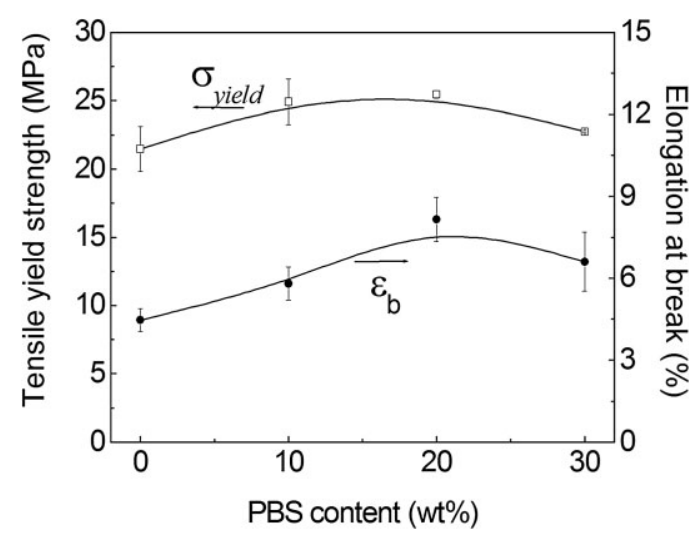

Figure 6. Tensile properties of the PHBV/PBS blends as a function of PBS content.

limit the range of its applications. The compatibilized PHBV/PBS blends show high tensile toughness but low notched impact toughness due to the strain rate dependence of toughness and the notch sensitivity of the materials. Meanwhile, the flexural modulus $\left(\sigma_{\text {f-yield }}\right)$ of the blends decreased with the DCP content. The crystallinity of PHBV and PBS for the physical PHBV/PBS (80:20) blends is (b)

around 27 and 36\%, respectively, according to DSC heating curves (not shown here). After addition of $0.5 \mathrm{wt} \% \mathrm{DCP}$, the crystallinity of PHBV did not change much, while the crystallinity of PBS reduced to $25 \%$. The reduction in crystallinity of PBS may account for the decrease in modulus after the in situ compatibilization.

\subsubsection{Toughening Mechanisms under Tensile Conditions}

The PHBV/PBS blends without DCP failed immediately after yielding. On the contrary, all compatibilized samples showed neck formation and neck growth indicating a tough behavior. The local deformation of rubber-toughened plastics is usually used to investigate the toughening mechanism of the blend. ${ }^{[27,28]}$ In order to study the toughening mechanism of the compatibilized PHBV/PBS blends, microscopic deformation of the morphology after drawing was characterized by SEM and TEM. The tensile bars after drawing were longitudinally cryofractured for SEM observations and cryomicrotomed for TEM characterization, as shown in Figure 7 and 8, respectively.

In Figure $7 \mathrm{a}$, the PBS particles in the physical blend were only slightly stretched because of low elongation at break. Due to the poor interfacial adhesion between the PBS and PHBV, the applied stress in the PHBV matrix could not be effectively transferred to the dispersed PBS phase via the interface. ${ }^{[20]}$ It causes the matrix to bear most of the stress, resulting in brittle behavior. In contrast, the compatibilized blends (Figure $7 \mathrm{~b}$ ) showed ductile behavior during drawing with $\varepsilon_{\mathrm{b}}$ up to $400 \%$. Also in Figure 8, it is shown that the dispersed PBS particles were

Table 1. Mechanical properties of the PHBV/PBS/DCP (80:20:X) blends; typical error for the data is 5 to $10 \% . \bar{D}_{\mathrm{p}}$ : number-average particle size of PBS; $\varepsilon_{b}$ : elongation at break; $\sigma_{\mathrm{i}}$ : notched Izod impact toughness; $\sigma_{\text {yield }}$ :yield tensile strength; $\sigma_{\text {f-yield: yield }}$ flexural strength; $M_{\mathrm{f}}$ : flexural modulus.

\begin{tabular}{lcccccc}
$\begin{array}{l}\text { DCP content } \\
\text { [wt\%] }\end{array}$ & $\begin{array}{c}\overline{\boldsymbol{D}}_{\mathbf{p}} \\
{[\boldsymbol{\mu \mathrm { m }}]}\end{array}$ & $\begin{array}{c}\varepsilon_{\mathbf{b}} \\
{[\%]}\end{array}$ & $\begin{array}{c}\sigma_{\mathbf{i}} \\
{\left[\mathbf{k J} \cdot \mathbf{m}^{-2}\right]}\end{array}$ & $\begin{array}{c}\sigma_{\text {yield }} \\
{[\mathbf{M P a}]}\end{array}$ & $\sigma_{\mathrm{f} \text {-yield }}$ & $\boldsymbol{M}_{\mathbf{f}}$ \\
\hline 0 & 0.55 & 8 & 2.8 & 25 & 39 & 1.2 \\
0.2 & 0.50 & 200 & 3.0 & 29 & 43 & 1.4 \\
0.5 & 0.24 & 400 & 5.0 & 28 & 32 & 0.7 \\
1.0 & 0.24 & 350 & 5.5 & 27 & 30 & 0.6
\end{tabular}

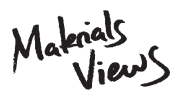

www.MaterialsViews.com
Macromol. Mater. Eng. 2011, 296, 000-000

(c) 2011 WILEY-VCH Verlag GmbH \& Co. KGaA, Weinheim 

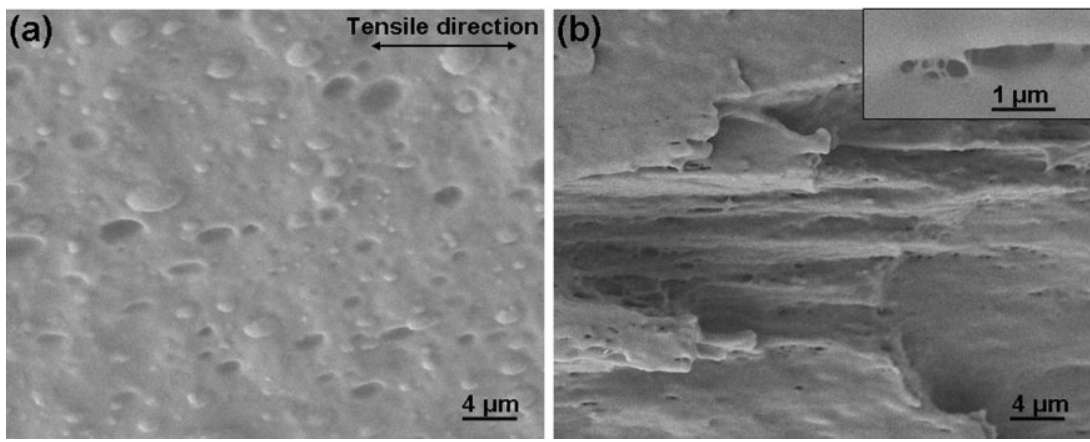

Figure 7. SEM images of the stretched PHBV/PBS (80:20) blends with DCP content of (a) 0 and (b) $0.5 w t \%$.
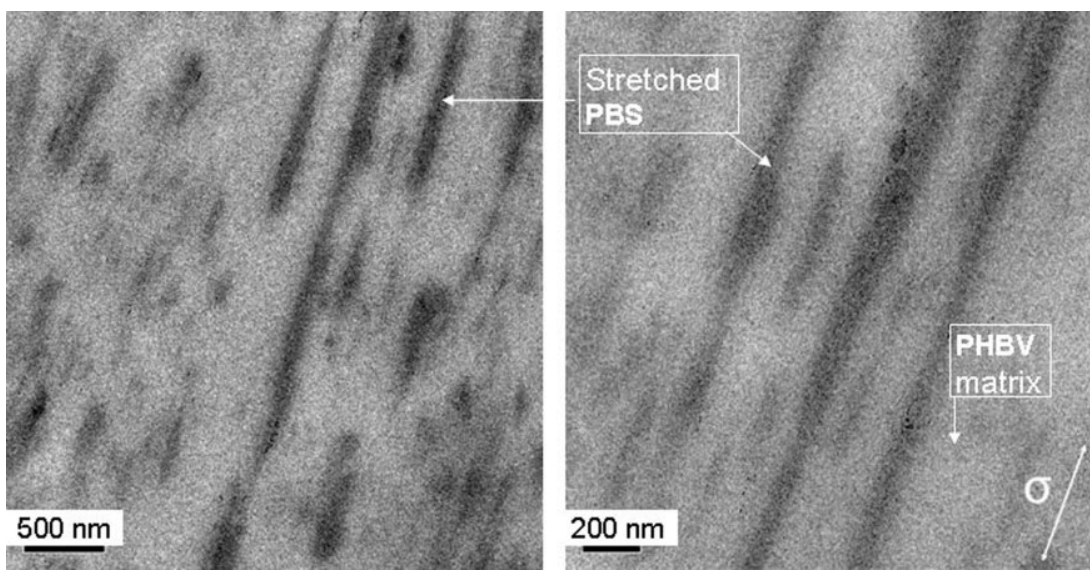

Figure 8. TEM images of the stretched PHBV/PBS/DCP (80:20:0.5) blend $\left(\varepsilon_{b}=400 \%\right)$.

largely elongated in the PHBV matrix. Due to the differences of Poisson ratio and bulk modulus between the PHBV and $\mathrm{PBS}$, the stress concentration was positioned around the PBS particles when a stress was applied, causing volume dilatation in the interior of the PBS particles. This type of microscopic deformation occurs when the interfacial adhesion is stronger than the stress concentrated at the interface between the PBS and PHBV, otherwise, interfacial debonding occurs. In rubber-toughened plastics systems, such dilatation could further result in internal rubber cavitation if the rubber particles are larger than a critical size and the shear modulus of the rubber is low. ${ }^{[29,30]}$ However, the SEM (Figure 7b) and TEM (Figure 8) images did not show traces of internal cavitation of the PBS particles, probably due to the partial crosslinking and crystallization of the PBS phase which increase the energy needed for creation of new surface. ${ }^{[29]}$ Furthermore, no multiplecrazing was observed in the PHBV/PBS/DCP blends after drawing (Figure 8). Consequently, the dilated PBS particles were highly deformed and oriented together with the PHBV matrix upon drawing (Figure 8). Somewhat fibrillized debonding was also observed (but was not general), as shown in the inset in Figure 7b. This kind of debonding indicates a high interfacial adhesion and can absorb a certain amount of energy. ${ }^{[31-33]}$ In addition, the PBS phase is partially crosslinked and possesses a lower crystallinity and a higher elasticity, ${ }^{[26]}$ which in combination with slightly crosslinked PHBV could also contribute to the toughness of the compatibilized blends.

The decrease in $\bar{D}_{\mathrm{p}}$ after compatibilization resulted in a dramatic increase in the number of PBS domains (Figure 5). The greater number of PBS domains reduced the inter-particle distance, which enabled the PHBV matrix to yield more easily. ${ }^{[34]}$ The matrix yielding is an important toughening mechanism for the in situ compatibilized PHBV/PBS blends.

In summary, the tensile toughness of the compatibilized PHBV/PBS blends is caused by the dilatation, deformation, and fibrillation of the PBS domains, the crystallinity reduction of PBS phase, the crosslink of the PHBV and PBS, and the matrix yielding.

\subsection{In situ Compatibilization of the PHB (homopolymer)/PBS Blends}

The PHB homopolymer is more brittle than PHBV but shows a higher stiffness and strength. Meanwhile, it is more available on the market at lower cost. In order to broaden the application range of the toughening method, in situ compatibilized PHB/PBS blends were compounded via melt extrusion and subsequently injection molded. Considering that DCP $0.5 \mathrm{wt} \%$ showed an optimum effect on properties of the PHBV/PBS system, a DCP content of $0.5 \mathrm{wt} \%$ was used for the PHB/PBS blends with PBS contents from 20 to 50 wt\%.

\subsubsection{Gel Fraction of the PHB (homopolymer)/PBS Blends}

The PHB/PBS/DCP blends were extracted by chloroform after reactive extrusion. The gel fraction is shown in Figure 9. At the same DCP content, the gel fraction of the PHB/PBS blend is nearly proportional to the PBS content. This is consistent with the former argument that PBS is more reactive in forming a network with peroxide. However, the overall gel fraction is lower than 25 wt\% when the PBS content is lower than $50 \mathrm{wt} \%$.

\subsubsection{Effect of Compatibilization on the Morphology of PHB (homopolymer)/PBS Blends}

Figure 10 shows the differences in morphology between the physical and the in situ compatibilized PHB/PBS blends. The 


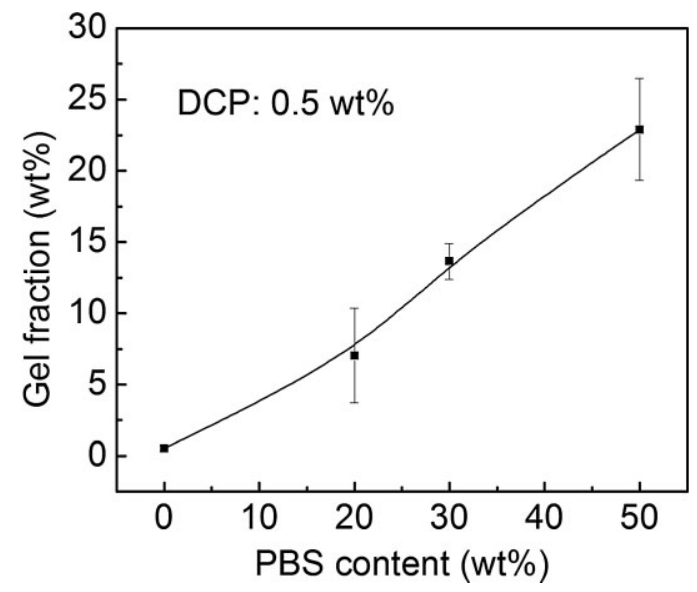

Figure 9. Gel fraction of the PHB/PBS/DCP blends as a function of PBS content.

final morphology of a polymer blend is a consequence of a dynamic equilibrium between break-up and coalescence of the droplets during melt-blending. Compatibilization is helpful for break-up and preventing coalescence of droplets. As expected, a significant reduction in average particle size $\left(\bar{D}_{\mathrm{p}}\right)$ of the PBS domains was observed after the in situ compatibilization. For example, the average diameter of
PBS particles $\left(\bar{D}_{\mathrm{p}}\right)$ in the PHB/PBS $(80: 20)$ blend is around $1 \mu \mathrm{m}$, which decreased by a factor of 3 after the in situ compatibilization.

The PHB/PBS (50:50) blend has co-continuous morphology which, after the in situ compatibilization, shows matrix-droplet morphology with a fine dispersion of PBS domains. The change in phase morphology of the PHB/PBS $(50: 50)$ blend is caused by the fact that the viscosity of both PHB and PBS phases was changed after addition of DCP, which affected the (critical) capillary number of the blend and enhanced the break-up of the PBS phase. Therefore, PBS tended to be a dispersed phase after addition of DCP. ${ }^{[35]}$ Meanwhile, the in situ formed compatibilizer, PHB-g-PBS copolymers, additionally restricted the coalescence of the PBS domains.

3.2.3. Mechanical Properties and Processability of the PHB (homopolymer)/PBS Blends

The overall mechanical properties of the PHB/PBS blends were improved after the in situ compatibilization, as shown in Table 2. The yield tensile strength ( $\left.\sigma_{\text {yield }}\right)$, the yield flexural strength $\left(\sigma_{\text {f-yield }}\right)$, the elongation at break $\left(\varepsilon_{\mathrm{b}}\right)$, the notched Izod impact toughness $\left(\sigma_{\mathrm{i}}\right)$, and the un-notched Izod impact toughness (Unnotched- $\sigma_{\mathrm{i}}$ ) were increased after the use of DCP. All specimen of the physical PHB/
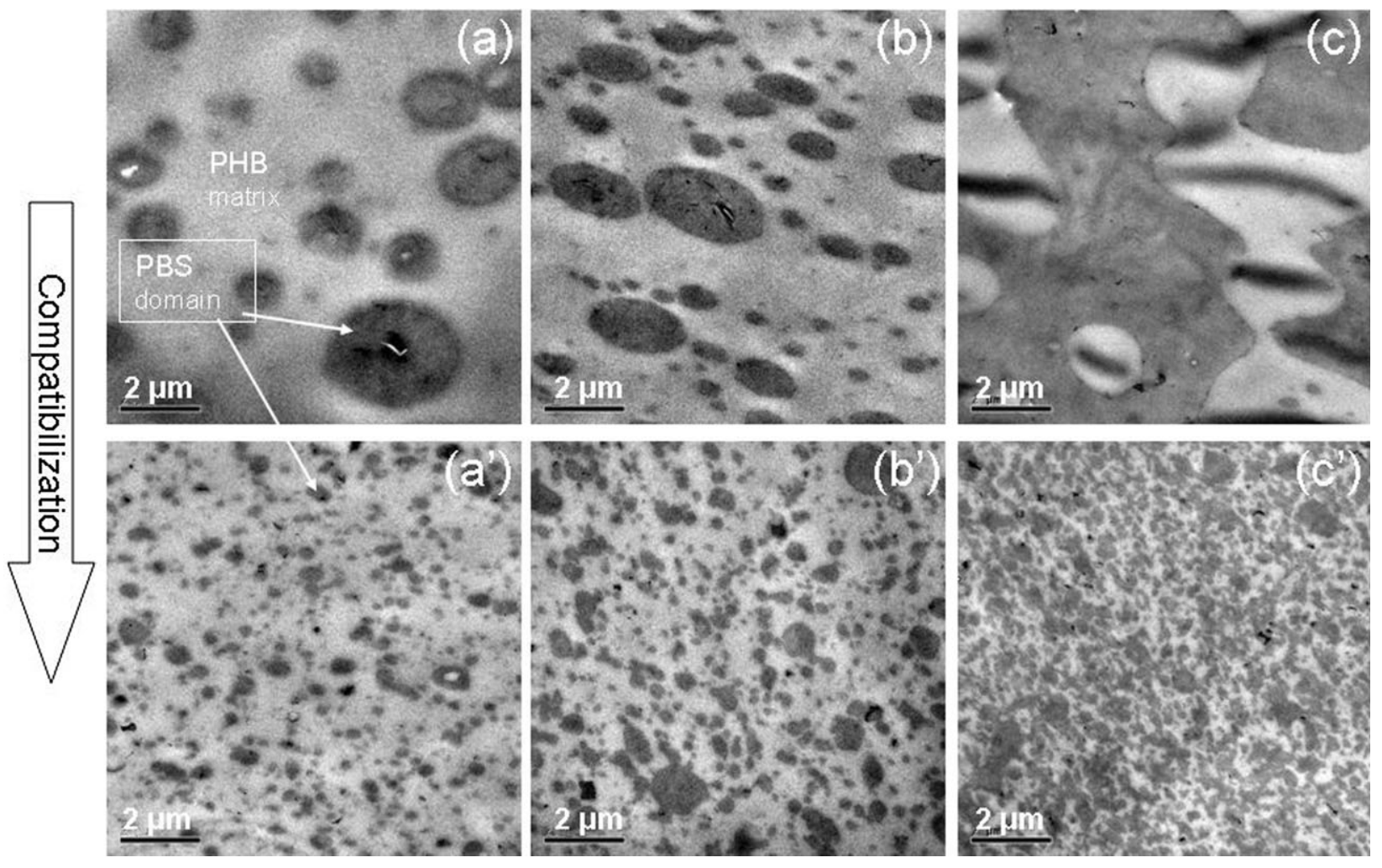

Figure 10. TEM images of the PHB/PBS blends: (a) PHB/PBS (80:20), (a') PHB/PBS/DCP (80:20:0.5), (b) PHB/PBS (70:30), (b') PHB/PBS/DCP (70:30:0.5), (c) PHB/PBS (50:50), and (c') PHB/PBS/DCP (50:50:0.5).

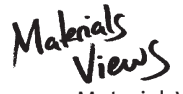

www.MaterialsViews.com 
Table 2. Mechanical properties of the PHB/PBS/DCP blends; typical error for the data is 5 to $10 \%$. Unnotched $\sigma_{\mathrm{i}}$ : un-notched Izod impact

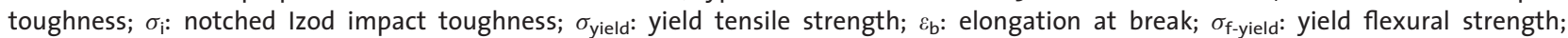
$M_{\mathrm{f}}$ : flexural modulus.

\begin{tabular}{lcccccc}
\hline $\begin{array}{l}\text { PHB/PBS/DCP } \\
\text { [wt\%] }\end{array}$ & $\begin{array}{c}\text { Unnotched } \sigma_{\mathbf{i}} \\
{\left[\mathbf{k J} \cdot \mathbf{m}^{-2}\right]}\end{array}$ & $\begin{array}{c}\sigma_{\mathbf{i}} \\
{\left[\mathbf{k J} \cdot \mathbf{m}^{-2}\right]}\end{array}$ & $\begin{array}{c}\sigma_{\text {yield }} \\
{[\mathbf{M P a}]}\end{array}$ & $\begin{array}{c}\varepsilon_{\mathbf{b}} \\
{[\%]}\end{array}$ & $\begin{array}{c}\sigma_{\mathbf{f} \text {-yield }} \\
{[\mathbf{M P a}]}\end{array}$ & $\begin{array}{c}\boldsymbol{M}_{\mathbf{f}} \\
{[\mathbf{G P a}]}\end{array}$ \\
\hline $100 / 0 / 0^{\text {a) }}$ & $/$ & 0.6 & 25 & 1 & 40 & 3.6 \\
$0 / 100 / 0^{\text {a) }}$ & $/$ & 6.5 & 35 & 260 & 34 & 0.6 \\
$80 / 20 / 0$ & 6 & 1.5 & 37 & 2 & 52 & 3.2 \\
$80 / 20 / 0.5$ & 17 & 3.5 & 40 & 4 & 60 & 2.3 \\
$70 / 30 / 0$ & 9 & 3.0 & 33 & 2 & 55 & 2.5 \\
$70 / 30 / 0.5$ & 54 & 4.0 & 38 & 11 & 60 & 2.0 \\
$50 / 50 / 0$ & 23 & 3.0 & 34 & 4 & 45 & 1.7 \\
$50 / 50 / 0.5$ & 82 & 5.5 & 37 & 15 & 54 & 1.5
\end{tabular}

a) Obtained from compression-molded samples.

PBS blends were easily fractured during un-notched Izod impact testing, while the specimen of the compatibilized PHB/PBS (70:30) and PHB/PBS (50:50) blends were only partially fractured or even not fractured under the same testing conditions. These results indicate a high un-notched impact toughness of the in situ compatibilized PHB/PBS blends.

However, the notched Izod impact toughness of these samples is still low, e.g., lower than that of a commercial high-impact poly(styrene) (HIPS, Styron A-Tech 1300), which was reported to be $136 \mathrm{~J} \cdot \mathrm{m}^{-1[36]}$ (i.e., $\approx 13.6 \mathrm{~kJ} \cdot \mathrm{m}^{-2}$ ). For injection-molded samples, orientation of polymer molecules may exist along the flow direction. Since all the tested bars were prepared under the same conditions and the tests were performed on the same direction, the effect of orientation is not discussed in this study. However, it has to be noted that the particle size and the viscosity of the blend components were changed by the in situ compatibilization, which changed the rheology of the materials as well ${ }^{[37]}$ and, thus, the extent of orientation may also be influenced. Because of the poor processability of PHB (very low melt viscosity, serious thermal degradation, and low crystallization rate), pure PHB and PHB/DCP specimen could not be successfully injection molded. This indicates that the melt processability of PHB could be obviously improved by addition of PBS.

After addition of DCP, the blends are still processable-can be extruded and injection molded using conventional devices. The gel formation did not sacrifice the processability of the PHB/PBS blends probably due to (i) the overall gel fraction of the blends is not too high $(<25 \mathrm{wt} \%)$, (ii) the matrix (i.e., PHB) which dominates the processability is not seriously crosslinked, and (iii) the melt-processing is accompanied by a thermal degradation of the matrix.

\section{Conclusion}

The compatibility between PHBV (or PHB) and PBS is poor, resulting in a relatively large particle size and a weak interfacial adhesion in their blends. To enhance their compatibility, an in situ compatibilization was performed on $\mathrm{PHB}(\mathrm{V}) / \mathrm{PBS}$ blends in the presence of DCP. During processing, DCP initiated a free-radical reaction between $\mathrm{PHB}(\mathrm{V})$ and $\mathrm{PBS}$ forming $\mathrm{PHB}(\mathrm{V})-\mathrm{g}$-PBS copolymers which subsequently acted as compatibilizer and partially crosslinked networks in the blends. SEM and TEM images showed that the size of PBS particles in the PHB or PHBV matrix decreased significantly after the in situ compatibilization, accompanied by an improvement of the interfacial adhesion. Consequently, the mechanical properties of the $\mathrm{PHB}(\mathrm{V}) / \mathrm{PBS}$ blends were improved. After addition of $0.5 \mathrm{wt} \%$ DCP, elongations at break from $<10$ to $400 \%$ for the PHBV/PBS $(80: 20)$ blend and un-notched Izod impact toughness values from 10 to $50 \mathrm{~kJ} \cdot \mathrm{m}^{-2}$ for the PHB/PBS (70:30) blend were observed.

However, the notched impact toughness of the PHBV/ PBS or PHB/PBS blends was still low after the in situ compatibilization, which means the notch sensitivity of the blends was not significantly improved. The local deformation mechanism of the PHBV/PBS/DCP blends under tensile conditions was studied using SEM and TEM. The results indicated that matrix yielding together with dilatation, deformation and fibrillation of the PBS particles, and partially crosslinking of the blends contributed to the enhanced toughness of the compatibilized blends. It is mainly the dispersed PBS phase in the blends that was crosslinked after addition of DCP, while the less crosslinked PHB or PHBV matrix retained the melt processability of the materials. The in situ compatibilization is effective in both 
PHBV(copolymer)/PBS and PHB(homopolymer)/PBS blends, demonstrating that this method is useful for different PHB grades.

In addition, crosslinked pure PHBV and pure PBS were reported to be fully biocompostable based on non-standard testing. ${ }^{[25,26]}$ Therefore, the biocompostability of the crosslinked $\mathrm{PHB}(\mathrm{V}) / \mathrm{PBS}$ blends is expected to remain.

Acknowledgements: The authors acknowledge A. B. Spoelstra and the Soft Matter Cryo-TEM Research Unit, Department of Chemical Engineering and Chemistry, Technique University of Eindhoven for microscopic morphology study using TEM.

Received: June 30, 2011; Published online: DOI: 10.1002/ mame.201100224

Keywords: blends; compatibilization; PBS; PHB; toughness

[1] C. S. Ha, W. J. Cho, Prog. Polym. Sci. 2002, 27, 759

[2] D. F. Parra, J. Fusaro, F. Gaboardi, D. S. Rosa, Polym. Degrad. Stab. 2006, 91, 1954.

[3] H. Yang, Z. Li, H. Qian, Y. Yang, X. Zhang, C. Sun, Polymer 2004, $45,453$.

[4] H. Alata, B. Hexig, Y. Inoue, J. Polym. Sci., Part B: Polym. Phys. 2006, 44, 1813

[5] L. M. W. K. Gunaratne, R. A. Shanks, Polym. Eng. Sci. 2008, 48, 1683.

[6] S. Wang, P. Ma, R. Wang, S. Wang, Y. Zhang, Y. X. Zhang, Polym. Degrad. Stab. 2008, 93, 1364

[7] R. Bhardwaj, A. K. Mohanty, L. T. Drzal, F. Pourboghrat, M. Misra, Biomacromolecules 2006, 7, 2044.

[8] Y. S. Chun, W. N. Kim, Polymer 2000, 41, 2305.

[9] Z. Oiu, W. Yang, T. Ikehara, T. Nishi, Polymer 2005, 46, 11814.

[10] J. Tao, C. Song, M. Cao, D. Hu, L. Liu, N. Liu, S. Wang, Polym. Degrad. Stab. 2009, 94, 575.
[11] J. Li, M. F. Lai, J. J. Liu, J. Appl. Polym. Sci. 2005, 98, 1427.

[12] Z. Oiu, T. Ikehara, T. Nishi, Polymer 2003, 44, 7519.

[13] Z. Oiu, T. Ikehara, T. Nishi, Polymer 2003, 44, 2503.

[14] L. Miao, Z. Oiu, W. Yang, T. Ikehara, React. Funct. Polym. 2008, 68, 446.

[15] A. Javadi, A. J. Kramschuster, S. Pilla, J. Lee, S. Gong, L. S. Turng, Polym. Eng. Sci. 2010, 50, 1440.

[16] B. Fei, C. Chen, H. Wu, S. Peng, X. Wang, L. Dong, J. H. Xin, Polymer 2004, 45, 6275.

[17] T. Fujimaki, Polym. Degrad. Stab. 1998, 59, 209.

[18] H. Song, S. Y. Lee, Enzyme Microb. Technol. 2006, 39, 352.

[19] J. Xu, B. H. Guo, Biotechnol. J. 2010, 5, 1149.

[20] M. F. Díaz, S. E. Barbosa, N. J. Capiati, Polymer 2007, 48, 1058.

[21] T. Semba, K. Kitagawa, U. S. Ishiaku, H. Hamada, J. Appl. Polym. Sci. 2006, 101, 1816.

[22] T. Semba, K. Kitagawa, U. S. Ishiaku, M. Kotaki, H. Hamada, J. Appl. Polym. Sci. 2007, 103, 1066.

[23] R. Wang, S. Wang, Y. Zhang, C. Wan, P. Ma, Polym. Eng. Sci. 2009, 49, 26.

[24] T. H. Abou-Aiad, M. Z. El-Sabee, K. N. Abd-El-Nour, G. R. Saad, A. El-Sayed, E. A. Gaafar, J. Appl. Polym. Sci. 2002, 86, 2363.

[25] B. Fei, C. Chen, S. Chen, S. Peng, Y. Zhuang, L. Dong, Polym. Int. 2004, 53, 937.

[26] D. J. Kim, W. S. Kim, D. H. Lee, K. E. Min, L. S. Park, I. K. Kang, I. R. Jeon, K. H. Seo, J. Appl. Polym. Sci. 2001, 81, 1115.

[27] Y. Li, H. Shimizu, Macromol. Biosci. 2007, 7, 921.

[28] L. Jiang, M. P. Wolcott, J. W. Zhang, Biomacromolecules 2006, 7, 199.

[29] D. Dompas, G. Groeninckx, Polymer 1994, 35, 4743.

[30] C. B. Bucknall, D. R. Paul, Polymer 2009, 50, 5539.

[31] G. M. Kim, G. H. Michler, Polymer 1998, 39, 5689.

[32] G. M. Kim, G. H. Michler, Polymer 1998, 39, 5699.

[33] K. A. Afrifah, L. M. Matuana, Macromol. Mater. Eng. 2010, 295, 802.

[34] S. Wu, Polymer 1985, 26, 1855.

[35] G. M. Jordhamo, J. A. Manson, L. H. Sperling, Polym. Eng. Sci. 1986, 26, 517.

[36] D. Li, H. Xia, J. Peng, M. Zhai, G. Wei, J. Li, J. Oiao, Radiat. Phys. Chem. 2007, 76, 1732.

[37] R. M. A. L’Abee, M. Van Duin, A. B. Spoelstra, J. G. P. Goossens, Soft Matter 2010, 6, 1758. 